\title{
EDITORIAL
}

\section{Summer Issue, 2018}

DOI:https://doi.org/10.5770/cgj.21.333

Hello! Our summer issue contains a wide range of topics ranging from a pilot study examining the effects of methylphenidate for apathy on visual attention scanning behavior, ${ }^{(1)}$ to an attempt to find a consensus on essential components of the physical exam in the setting of a primary care-based memory clinic. ${ }^{(2)}$ Other papers examine the factors involved in the delay between the onset of symptoms and clinical assessment at a memory clinic, ${ }^{(3)}$ guidelines for gait assessments in the Canadian Consortium on Neurodegeneration in Aging (CCNA), ${ }^{4)}$ a systematic review of the national dementia strategies of various countries, ${ }^{(5)}$ and an evaluation of Twitter use at the 2017 Canadian Geriatrics Society conference in Toronto, Canada. ${ }^{(6)}$
Thanks again for your interest!

Cheers,

Dr. Ken Madden

Dr. Mark Rapoport

Dr. Colleen Maxwell

Canadian Geriatrics Journal

\section{REFERENCES}

1. Chau SA, Herrmann N, Chung J, et al. Effect of methylphenidate for apathy on visual attention scanning behavior: a pilot study. CGJ. 2018;21(2):139-142.

2. Heckman GA, Franco BB, Lee L, et al. Towards consensus on essential components of physical examination in primary care-based memory clinics. CGJ. 2018;21(2):143-151.

3. Claveau J-S, Presse N, Kergoat M-J, et al. The lost years: delay between the onset of cognitive symptoms and clinical assessment at a memory clinic. CGJ. 2018;21(2):152-156.

4. Cullen S, Montero-Odasso M, Bherer L, et al. Guidelines for gait assessments in the Canadian Consortium on Neurodegeneration in Aging (CCNA). CGJ. 2018;21(2):157-165.

5. Chow S, Chow R, Wan A, et al. National dementia strategies: what should Canada learn? CGJ. 2018;21(2):173-209.

6. Cheung B, Wong CL, Gardhouse A, et al. \#CGS2015: An evaluation of Twitter use at the Canadian Geriatrics Society Annual Scientific Meeting. CGJ. 2018;21(2):166-172. 